\title{
Erratum to: An Enhanced Security Solution for Electronic Medical Records Based on AES Hybrid Technique with SOAP/XML and SHA-1
}

M. L. Mat Kiah • Mohamed S. Nabi • B. B. Zaidan •

A. A. Zaidan

Published online: 20 January 2015

(C) Springer Science+Business Media New York 2015

Erratum to: J Med Syst (2013) 37:9971

DOI 10.1007/s10916-013-9971-2

The original version of this article unfortunately contained an error. The university of the first affiliation should be changed from "University of Malaysia" to "University of Malaya". The update is provided here as well.

The online version of the original article can be found at http://dx.doi.org/ 10.1007/s10916-013-9971-2.

M. L. M. Kiah • M. S. Nabi • B. B. Zaidan · A. A. Zaidan Faculty of Computer Science and Information Technology,

University of Malaya, 50603 Kuala Lumpur, Malaysia

B. B. Zaidan $\cdot$ A. A. Zaidan $(\bowtie)$

Faculty of Engineering, Multimedia University, Jalan Multimedia,

Cyberjaya 63100, Selangor Darul Ehsan, Malaysia

e-mail: aws.alaa@gmail.com 